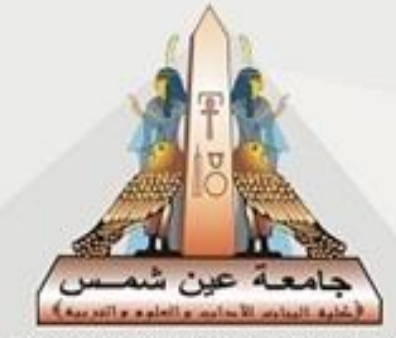

Faculty of Women for, Arts,

Science, and Education

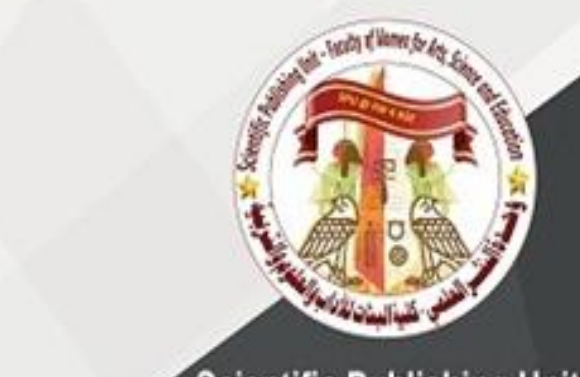

Scientific Publishing Unit

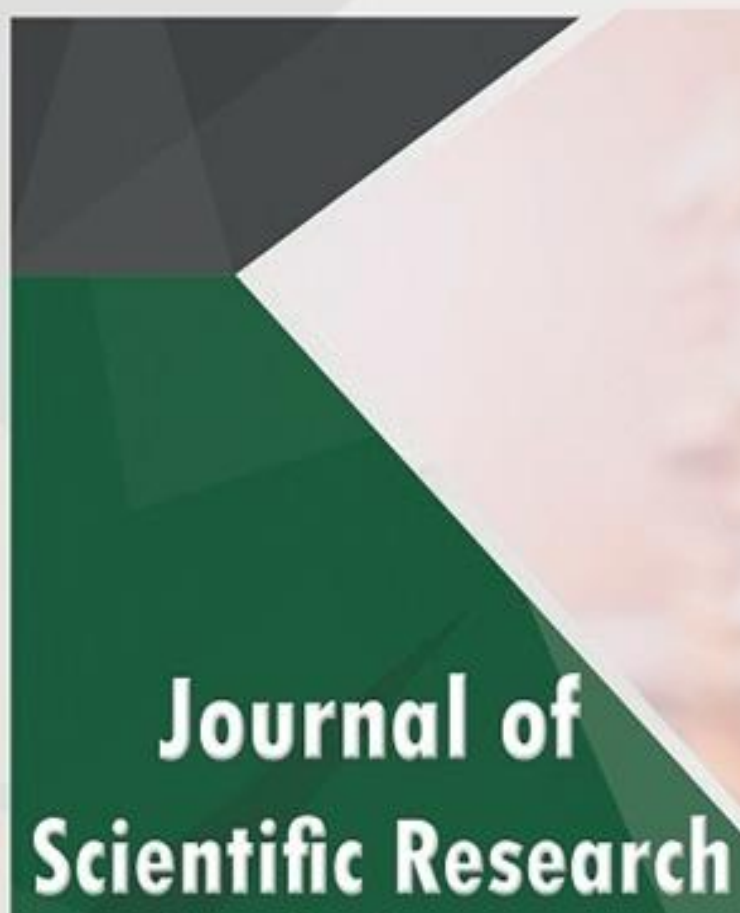

in Science

Basic Sciences

Volume 38, Issue 1, 2021

ISSN 2356-8372 (Online) \ISSN 2356-8364 (print)

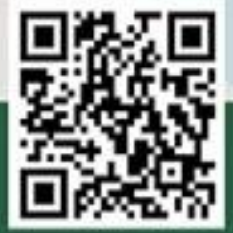


Journal of Scientific Research in Science 2021, 38, (1): 1-18

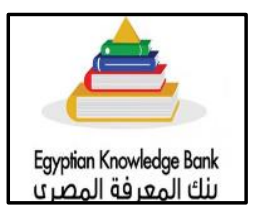

Contents lists available at EKB

Journal of Scientific Research in Science

Journal homepage: https://jsrs.journals.ekb.eg/

\title{
Evaluative study between calculated and measured DVHs for advance techniques of radiotherapy for Prostate Cancer Patients
}

\author{
Ibrahim El Hamamsi 1, *, Khaled M. Elshahat ${ }^{2}$, A. EL-Shershaby ${ }^{1}$, T.M. Hegazy ${ }^{1}$ \\ ${ }^{1}$ (Physics Department, Faculty of Women for Arts, Science and Education, Ain Shams \\ University, Egypt). \\ ${ }^{2}$ (Clinical Oncology and Nuclear Medicine Department, Faculty of Medicine, Al Azhar \\ University, Egypt).
}

\begin{abstract}
:
This study aims to use 3DVH software (Sun Nuclear Corporation, Melbourne, FL, USA) to compare the dose that was predicted by treatment planning system (TPS) with the measured dose obtained by ArcCHECK dosimetric device using two advance treatment techniques: Volumetric Modulated Arc Therapy (VMAT) and Intensity Modulated Radiation Therapy (IMRT). Thirty prostate cancer patients who were treated with VMAT and re- planned with IMRT using Eclipse planning system were studied. The percentage dose differences (\%DDs) were calculated using 3DVH software for planning target volume (PTV) and risk organ (OARs). The correlations between \%DD and the gamma pass rate (GPR) $(3 \% / 3 \mathrm{~mm}, 2 \% / 2 \mathrm{~mm}$ and $1 \% / 1 \mathrm{~mm})$ criterion were examined. Both the DVHs calculated by 3DVH and the one projected by TPS were compared using the different parameters for PTV and OAR. In VMAT technique, the \%DD was less than 3\% for PTV and 4\% for OAR while the IMRT technique recorded \%DD less than $2 \%$ for PTV and $4 \%$ for OAR. 3DVH was somewhat more consistent with the planned VMAT verification data compared to ArcCHECK, with a mean gamma pass rate of $99.34 \%$ for the $3 \% / 3 \mathrm{~mm}$ criterion Based on our results, VMAT is especially beneficial for prostate most cancers treatment.
\end{abstract}

Keywords: 3DVH, QA, ArcCHECK, Gamma Pass Rate

\section{Introduction}

Prostate cancer (PC) is a very prevalent health issue. It begins to develop around the age of 50, with the peak occurring between the ages of 60 and 70 [1]. The advanced form of 3D conformal radiation (3D-CRT) combined with a non-uniform intensity of the beam to increase dose homogeneity and distribution is Intensity Modulated Radiation Therapy (IMRT) [2]. IMRT has dosimetrical benefits over 3D-CRT due to the steep dose gradients and the tight conformal

*Corresponding author: Ibrahim El Hamamsi, Physics Department, Faculty of Women for Arts, Science and Education, Ain Shams University, Egypt.

E-mail: phy.ibrahim@yahoo.co.uk 
doses. These advantages make it possible to lower the dose to the bladder and/or rectum in this case and result in reduced toxicity.

The term "IMRT" indicates a radiation oncology procedure in which the patient receives non-uniform fluence from the direction of the treatment beam to optimize the composite dose distribution. The processing requirements for optimizing the plans are specified by the planner and through the "inverse planning", the optimal fluence profiles for a particular set of beam directions are determined [3].

VMAT is a modern technique of delivering IMRT, it generates IMRT distributions in a single arc rotation, adjusting the dose rate and the gantry speed, as opposed to standard IMRT with fixed gantry beams [4,5]. VMAT can guarantee high doses conformation while preventing healthy tissue by minimizing the number of MU over treatment. The classical IMRT plan produces a number of segment fields designed by the MLC with several fixed gantry angles, by sequentially moving MLC to various orientations and then deliver the radiation dose as in step-and-shoot method or with constant MLC movement as in sliding window method.

Currently, the majority of pretreatment QA for IMRT and VMAT plans is measurementbased. A variety of approaches can be utilized for measurements, with the standard workflow consisting of recalculating the accepted treatment plan on a dosimeter and then irradiating in the same geometry [6]. In advance treatment techniques such as IMRT and VMAT, pretreatment quality assurance (QA) is managed using electronic portal imaging devices (EPIDs) attached to a linear accelerator. This helps to determine the possibility of a discrepancy between the estimated dose by TPS and the delivered dose by the linear accelerator [7]. The patient specific QA plan is performed before the patient's first treatment session where all the fields are set to zero, and the dose fluence from the TPS is validated using the obtained outputs. Pretreatment QA is recommended for IMRT plans to compare the photon fluence maps delivered by continuous movement of MLC [8]. Different QA tools such as films, ionization chambers, two-dimensional (2D) detector arrays, three-dimensional (3D) detectors, and gel dosimeters have been used overtime [9,10]. Gravitational sagging of linear accelerator (LINAC) head and EPID tail can affect the quality assurance. A possible cause of treatment error as indicated by Ezzell et al. [11] is the corruption of treatment related files during transfer of data from the TPS to a linear accelerator. 
Due to narrow margins and high dose gradient of IMRT and VMAT, these subtle effects may have major effects on the overall dose distribution and require specific commissioning and continuously QA of both the treatment machine and TPS.

The uncertainties in the treatment process indicate the importance of patient-specific pretreatment quality assurance (QA) of treatment plans to check the accuracy of dose estimates and detect clinically significant inaccuracies in radiation delivery [12]. This work helps to evaluate the accuracy of IMRT and VMAT treatment plans for prostate cancer patients and the objective is to compare the $3 \mathrm{DVH}$ software with a 3D pre-treatment QA system for two different advanced techniques.

\section{Material and Method}

\subsection{Patient selection, preparation, and radiation delivery}

TPS “Eclipse” V 13.7.14 was used to generate treatment plans for thirty prostate cancer patients who received 76 Gy in 38 fractions with IMRT and VMAT. These plans were calculated using photon beams with an energy of $10 \mathrm{MV}$ from the Clinac® iX System. Five fields $\left(140^{\circ}, 60^{\circ}\right.$, $0^{\circ}, 300^{\circ}$, and $220^{\circ}$ ) were optimized by setting the collimator and couch to zero. Whereas VMAT plans used clockwise $(\mathrm{CW})$ and counterclockwise (CCW) partial arcs (from $230^{\circ}$ to $130^{\circ}$ ) with collimator rotation $\left(15^{\circ} / 345^{\circ}\right)$ respectively. Using the anisotropic analytical algorithm (AAA), all dose calculations were performed in Eclipse planning system. Verification plans were created in Eclipse v13.7.14 using the ArcCHECK phantom. ArcCHECK phantom is a cylindrical phantom with a 3D array of 1386 diode detectors organized in a spiral design and spaced at $10 \mathrm{~mm}[13,14]$. The predicted distribution of dose was interpreted using ArcCHECK V6.7.3 and 3DVH V 3.3.1.

\subsection{Gamma Analysis}

The most widely used method for quantitative analysis of the comparison between planned and predicted isodose distributions for IMRT and VMAT treatments is gamma analysis which was first presented by Low, Harms, Mutic, \& Purdy (1998). By comparing the dose distribution based on both dose and spatial domains, the gamma analysis approach works. Based on user defined 
acceptance condition, it quantifies the quality of the comparison using a single composite measure, in terms of \%DD and (DTA) [15].

$\% \mathrm{DD}$ is essentially the percentage difference between the planned and measured dose, and the points are considered a pass if they are within the user-defined acceptance condition. The $3 \%$ dose difference is the most commonly used acceptance criterion for the percent dose difference between the planned and measured IMRT QA data [16].

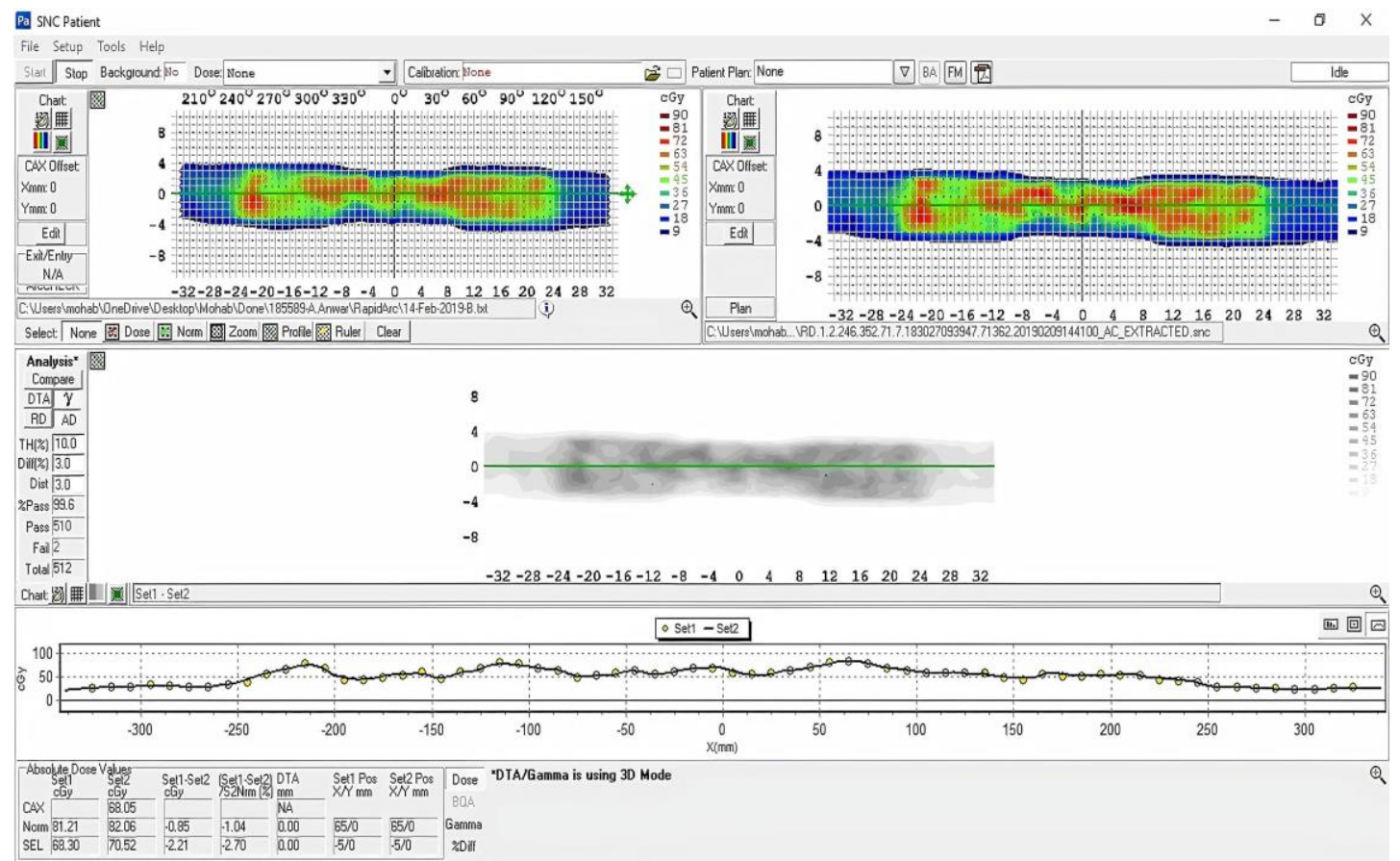

Fig (1): The measured ArcCHECK dose points are shown in a 2D dose analysis generated by SNC patient software

\subsection{Dose Differences}

Among other research, AAPM TG 119 assessed the patient acceptability levels of QA and recommended the criterion of the distance-to-agreement to be $3 \%$ and $3 \mathrm{~mm}$ [17]. Predicted dose distributions were analyzed using the $1 \% / 1 \mathrm{~mm}, 2 \% / 2 \mathrm{~mm}$, and $3 \% / 3 \mathrm{~mm}$ criteria in this study. The dose difference with ACPDP calculator was evaluated by 3DVH software (Fig. 1). The dose 
difference between the collected doses rebuilt by 3DVH software and the TPS calculations and was evaluated. The \%DDs were calculated with 3DVH software for the PTV and the OARs. The correlations between \%DD and GPR were also examined with Microsoft Office Professional plus Excel 2016. The Dose Volume Histograms estimated by 3DVH were compared with the DVHs projected by the planning system using these parameters: $\mathrm{D}_{\text {Mean }} \&$ D98 for PTV, D Mean \& V50 for Rectum and Bladder, $\mathrm{D}_{\text {Mean }}$ for femoral heads. The percentage dose difference $\%$ DD is defined as:

\section{$\% \mathrm{DD}=\left(\mathbf{D}_{3 \mathrm{DVH}}-\mathrm{D}_{\mathrm{TPS}}\right) / \mathrm{D}_{\mathrm{TPS}} \times \mathbf{1 0 0}$}

$\mathrm{D}_{3 \mathrm{DVH}}$ represents the dose estimated by 3DVH, whereas $\mathrm{D}_{\text {TPS }}$ denotes the dose calculated by the TPS. We investigated the pass rates of the gamma index with the purpose of comparing the dose distributions measured by ArcCHECK with the calculated dose distributions by TPS.

\subsection{ArcCHECK patient-specific QA protocol}

ArcCHECK is a 3D dosimetry QA system designed to quantify the dose distribution of radiotherapy delivered, as well-defined by a TPS. It's also a cylindrical water equivalent phantom with a 3D arrangement of 1386 diode detectors, placed in a $10 \mathrm{~mm}$ sensor spacing in spiral pattern [18].

\subsection{DVH Analysis}

3D dosimetric verification was conducted by 3DVH. In this study, the dose inaccuracies (due to measured vs calculated dose phantoms) are used to pertrub the original 3D dose and to precisely predict the $3 \mathrm{D}$ patient dose. $3 \mathrm{DVH}$ is a software application for comparing $3 \mathrm{D}$ dose and DVHs during the dose delivery of QA plan. One dataset is imported as calculated and created by a (TPS) as part of a prescribed dose plan, the other is analyzed by 3DVH [18]. 3DVH can be used to compare any 3D plan to any other 3D plan, including competing modalities and vendors or treatment planning systems. The 3DVH utilizes the PDP algorithm (Fig. 2) to estimate the delivered dose to the patient and the DVH computed by advanced techniques [19]. 


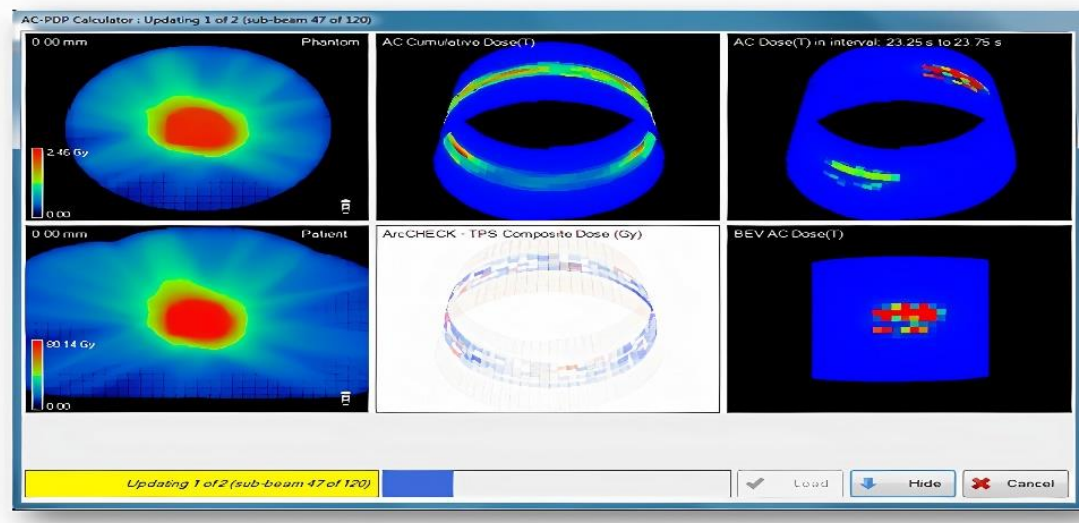

Fig (2): Calculation of ArcCHECK Planned Dose Perturbation (ACPDP) in 3DVH software

\subsection{Analysis of dose volume histogram (DVH)-based metrics}

A paired t-test was utilized to compute the difference in statistics between IMRT and VMAT and statistically significant p-values were less than 0.05 . Pearson correlation analysis was also used to investigate the relationship in the dose deviation between 3D-GPR and the DVHbased metrics for the PTV and the OARs.

\section{Results}

Two metrics were used for the data analysis of this study: DVH-based and gamma analysis. 3DVH software was used to calculate these DVH-based metrics: for PTV ( $\mathrm{D}_{\text {mean }}$ and $\left.\mathrm{D}_{98 \%}\right)$, for bladder walls and rectum (mean dose and V50Gy) while left femur and right femur (mean dose). DVHs provided by the 3DVH were compared with the planned dose distribution calculated by treatment planning system (Eclipse) V13.7.14. The mean DVH values obtained using both 3DVH and TPS were calculated for both VMAT and IMRT techniques. A t-test statistical analysis between the mean values was carried out to verify the procedures used in this study that were affected by systematic errors. Table 1 present the values of mean gamma pass rates of 3DVH and ArcCHECK for IMRT and VMAT. 
Table (1): The mean Gamma pass rates of 3DVH and ArcCHECK for IMRT and VMAT

\begin{tabular}{|c|c|c|c|c|}
\hline & \multicolumn{2}{|c|}{ IMRT } & \multicolumn{2}{c|}{ VMAT } \\
\hline GPR & 3DVH & ArcCHECK & 3DVH & ArcCHECK \\
\hline $1 \% / 1 \mathrm{~mm}$ & $68.59 \pm 6.32$ & $57.87 \pm 6.62$ & $85.05 \pm 3.54$ & $67.76 \pm 9.90$ \\
\hline $2 \% / 2 \mathrm{~mm}$ & $90.95 \pm 2.34$ & $85.99 \pm 3.57$ & $97.80 \pm 0.54$ & $93.55 \pm 4.14$ \\
\hline $3 \% / 3 m m$ & $98.03 \pm 0.99$ & $96.79 \pm 1.41$ & $99.34 \pm 0.22$ & $99.11 \pm 0.66$ \\
\hline
\end{tabular}

In IMRT plans, the mean gamma pass rates of ArcCHECK and 3DVH were estimated to be lower than those of VMAT plans. 3DVH presented a somewhat better agreement with planned data for VMAT verifications with a mean gamma pass rate of $99.34 \%$ for $3 \% / 3 \mathrm{~mm}$ criterion compared to that of ArcCHECK. Table 2 shows the percent \%DDs for the PTV and OAR between the TPS and ArcCHECK measurements for both techniques. For the VMAT technique, the \%DD was less than $3 \%$ for PTV and $4 \%$ for normal organs (OARs). The gamma pass rate GPR was correlated with the \%DD for $\mathrm{D}_{\text {Mean }}$ and $\mathrm{D}_{98}$ of PTV, $\mathrm{D}_{\text {Mean }}$ and $\mathrm{V}_{50}$ of Rectum \& Bladder, and $\mathrm{D}_{\text {Mean }}$ and $\mathrm{D}_{\text {Max }}$ of Femoral heads (p0.05). These findings indicated a strong correlation $(r>0.7)$.

However, the \%DD of IMRT technique was lower than that of VMAT. There was no statistically significant difference. Fig.3a, 3b, 4a and 4b illustrates the relationship of \%DD and the GPR for each volume. For both techniques, the \%DD for the mean dose of PTV becomes smaller as GPR increases. However, for all volumes except the Rectum and right Femur in IMRT, there was no discernible correlation. 
Table (2): Data showing DVH parameters calculated by the TPS Eclipse and by the 3DVH Software for PTVs and OARs and the relative $p$ value

\begin{tabular}{|c|c|c|c|c|c|c|c|c|c|}
\hline \multicolumn{5}{|c|}{ VMAT } & \multicolumn{5}{|c|}{ IMRT } \\
\hline Structure & Parameter & $\% D D$ & $r$ & $\begin{array}{c}p- \\
\text { value }\end{array}$ & Structure & Parameter & $\% D D$ & $r$ & $\begin{array}{c}p- \\
\text { value }\end{array}$ \\
\hline PTV & DMean & 2.019 & 0.6939 & $<0.05$ & PTV & DMean & 0.485 & 0.492 & $>0.05$ \\
\hline PTV & D98\% & 2.265 & 0.6658 & $<0.05$ & PTV & D98\% & 1.183 & 0.799 & $<0.05$ \\
\hline Rectum & DMean & 1.9 & 0.9966 & $<0.05$ & Rectum & DMean & 3.211 & 0.998 & $<0.05$ \\
\hline Rectum & V50Gy & 3.23 & 0.9982 & $<0.05$ & Rectum & V50Gy & 3.612 & 0.997 & $<0.05$ \\
\hline Bladder & DMean & 0.291 & 0.9994 & $<0.05$ & Bladder & DMean & 0.325 & 0.999 & $>0.05$ \\
\hline Bladder & V50Gy & 1.595 & 0.9987 & $<0.05$ & Bladder & V50Gy & 2.23 & 0.999 & $<0.05$ \\
\hline $\begin{array}{c}\text { Lt. } \\
\text { Femur }\end{array}$ & DMean & 0.97 & 0.9988 & $<0.05$ & $\begin{array}{c}\text { Lt. } \\
\text { Femur }\end{array}$ & DMean $_{1}$ & 3.081 & 0.999 & $<0.05$ \\
\hline Rt. & DMean & 0.78 & 0.9995 & $<0.05$ & Rt. & DMean & 2.146 & 0.999 & $<0.05$ \\
\hline
\end{tabular}

\section{Discussion}

To recognize any possible errors in the treatment planning process and machine deliverability, advanced dosimetric techniques are strongly recommended for patients-specific pre-treatment verification and are regularly performed in many clinics [9]. Radiotherapy QA has historically used a combination of irradiation methods by using an ion chamber or film, or a beamby-beam irradiation method by the usage of diode or ion-chamber arrays [20]. However, the 3DVH software and a 3D detector such as ArcCHECK can be used to gather a large amount of data quickly and easily. The use of a 3D instead of a 2D diode array enables each beam's eye view data to be obtained in every field; both entry and exit dose values can be attained as well [21]. Composite data with the information obtained from each beam can be generated using the 3DVH software.

The ArcCHECK 2D diode array is a detector arrangement designed to verify treatment plans [20]. Guangjun et al, in their research verified the simple plan of four beams of different field sizes and 10 IMRT and 10 VMAT plans of various cancer sites with varying complexity. In their pre-treatment verifications results for all the IMRT and VMAT plans, both ArcCHECK and ion chamber data revealed good agreement. This implies that the ArcCHECK QA system was 
effectively designed for verification of IMRT and VMAT treatments, and that TPS estimated precision and linear accelerator delivery for IMRT and VMAT treatments may be achieved for clinical scenarios [22].

In this research, patient specific pretreatment QA using ArcCHECK dosimetric equipment was carried out and 3DVH software was assessed. Moreover, for the PTV and OARs, the \%DD and the GPR were assessed. The ArcCHECK-3DVH has been recommended by some authors, such as Infusino et al [23], who in their work evaluated the suitability of the ArcCHECK and 3DVH system for VMAT. Their Dose-volume histogram (DVH) analysis for patient plans revealed small differences between treatment plan calculations and 3DVH results for organ at risk (OAR), while planning target volume (PTV) of the measured plan was higher than that predicted by the TPS. The goal of our research is to carry out advanced techniques QA with the ArcCHECK and compare the outcomes to those of the 3DVH. This cylindrical phantom and 3DVH software were used to assess the gamma pass rate. Despite the fact that the outcomes for both treatment methods were very similar.

IMRT causes an increase in MU compared to VMAT which results in an increased integral dose. The decrease of MUs required for VMAT minimizes the leakage of the gantry head, which increases the risk for secondary malignancies. However, VMAT provides a dosage around the patient, possibly resulting in an increment in tissue volume exposed to low-level radiation doses [24]. While we observed that the MUs with VMAT are substantially less than IMRT, the distribution of both dosage and leakage radiation are important when depositing dose beyond the volume of treatment. 

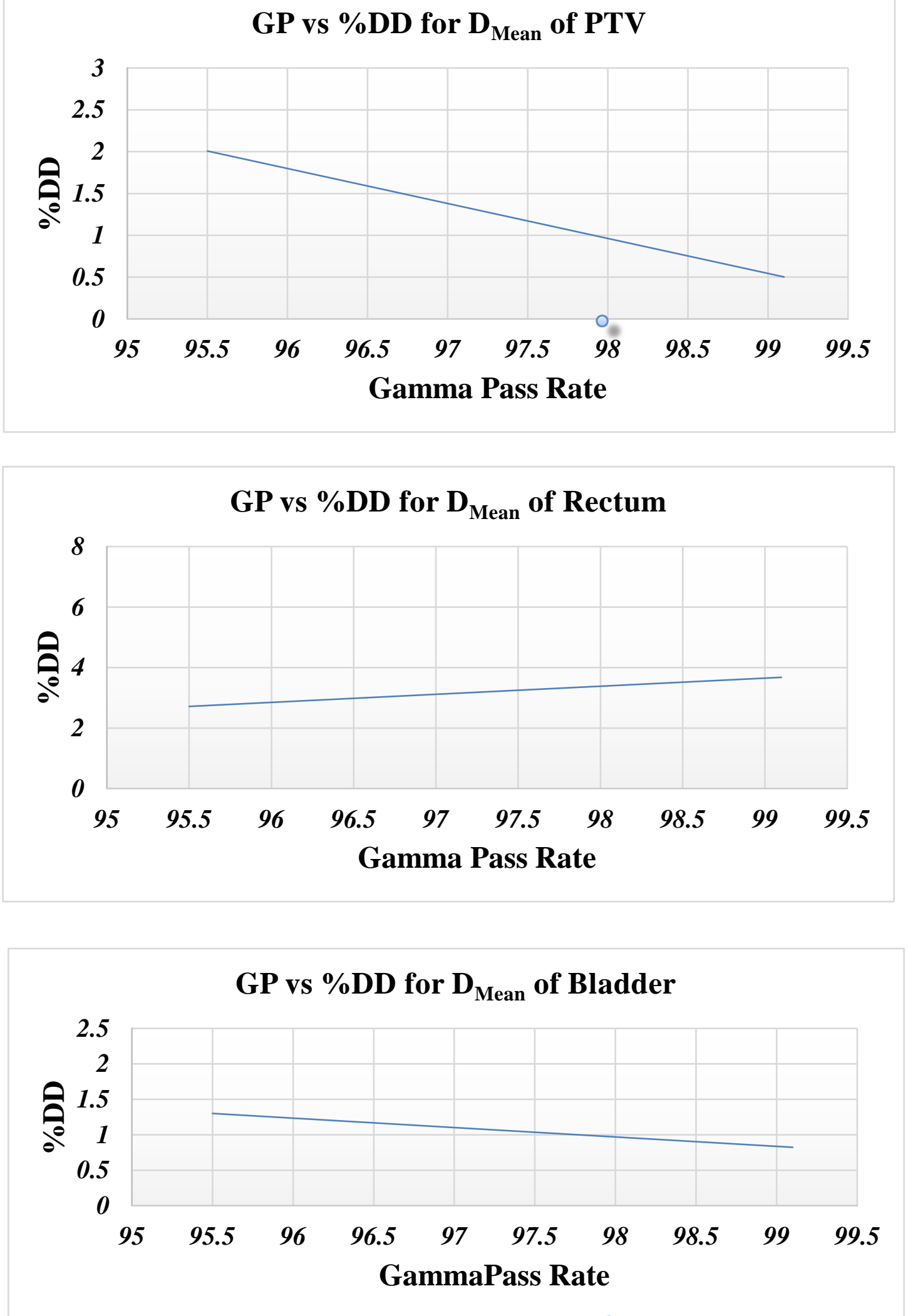

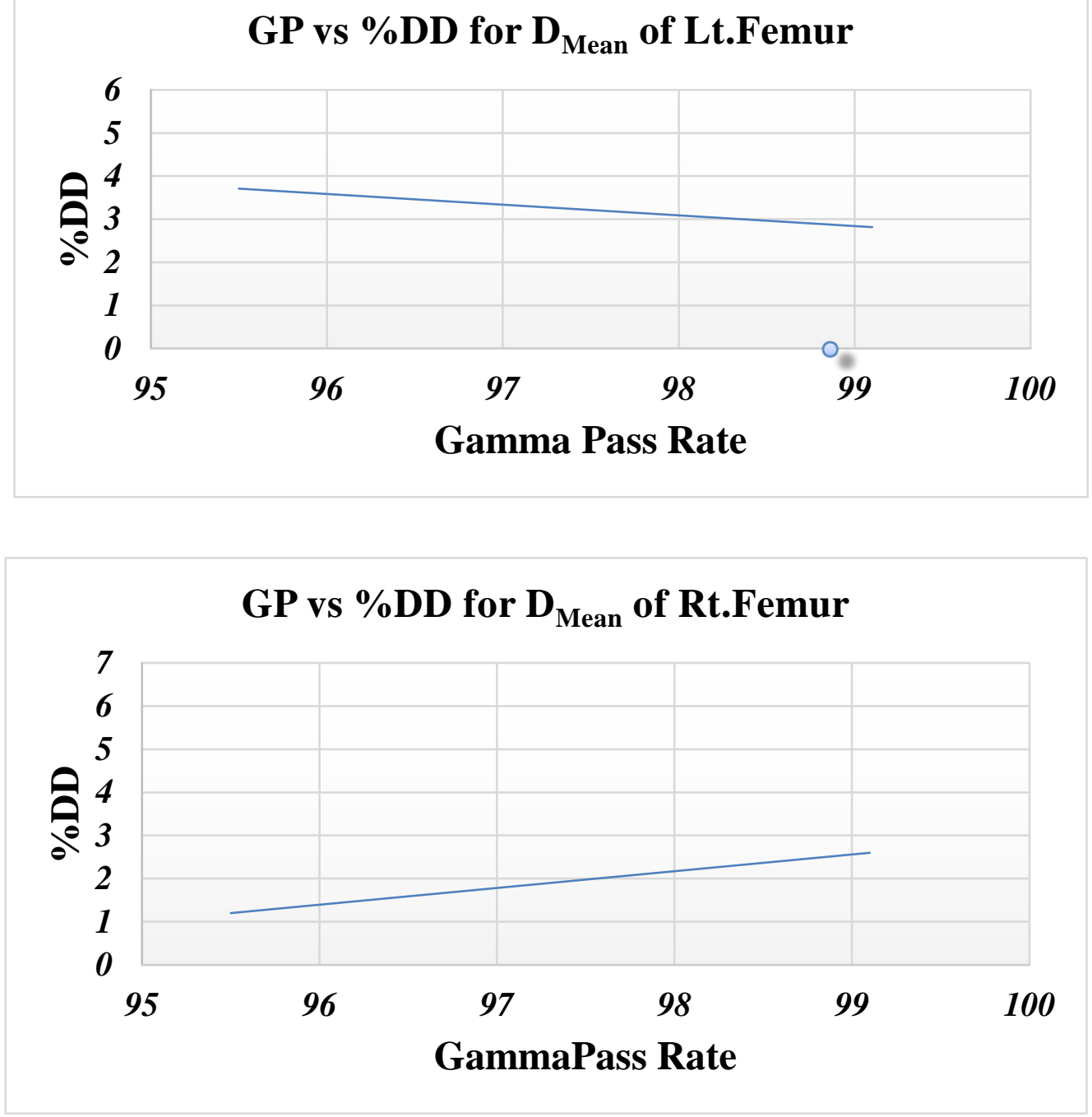

Fig 3b: Relationship between gamma pass rate GPR and \%DD for each structure using 

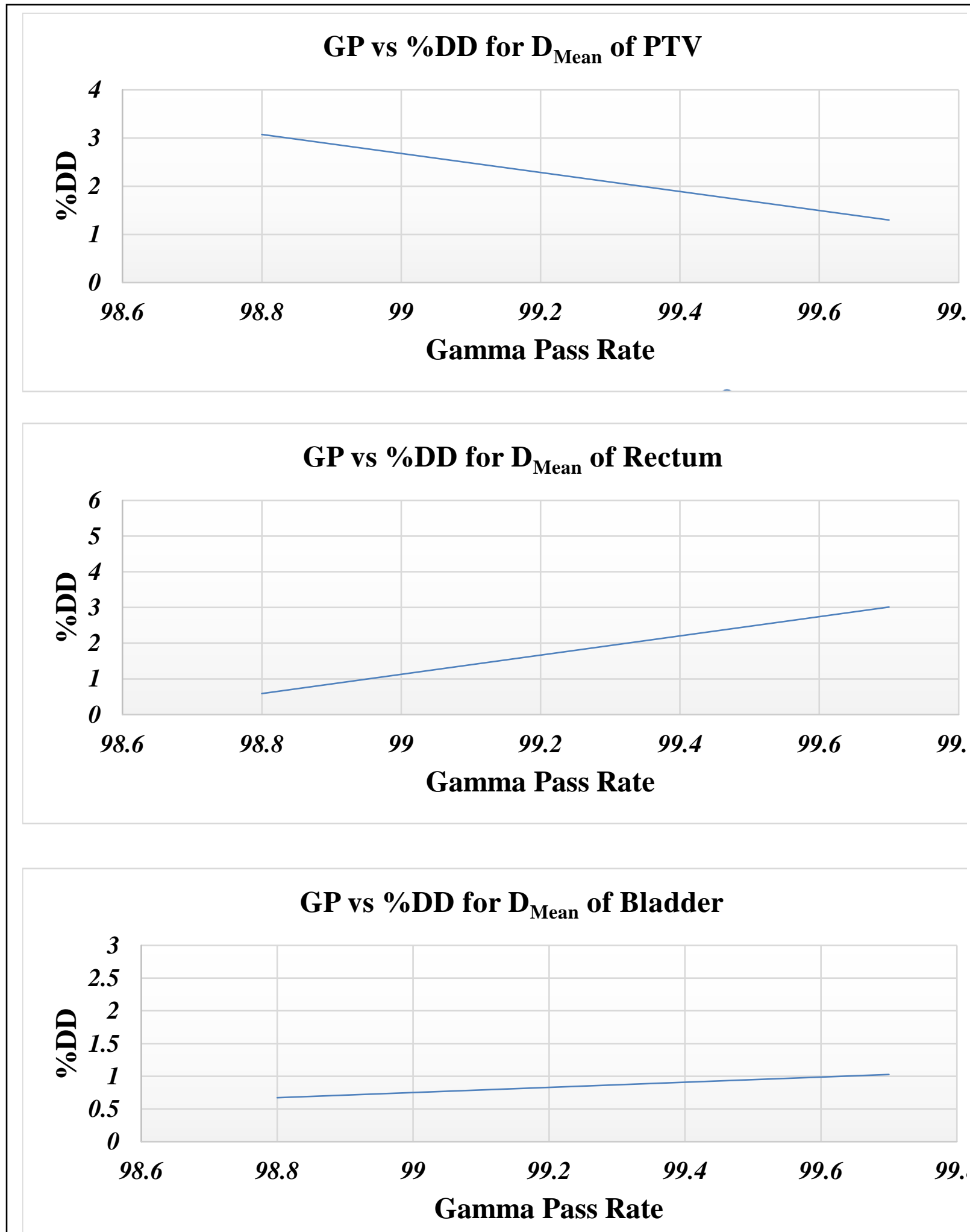

Fig 4a: Relationship between gamma pass rate GPR and \%DD for each structure using 


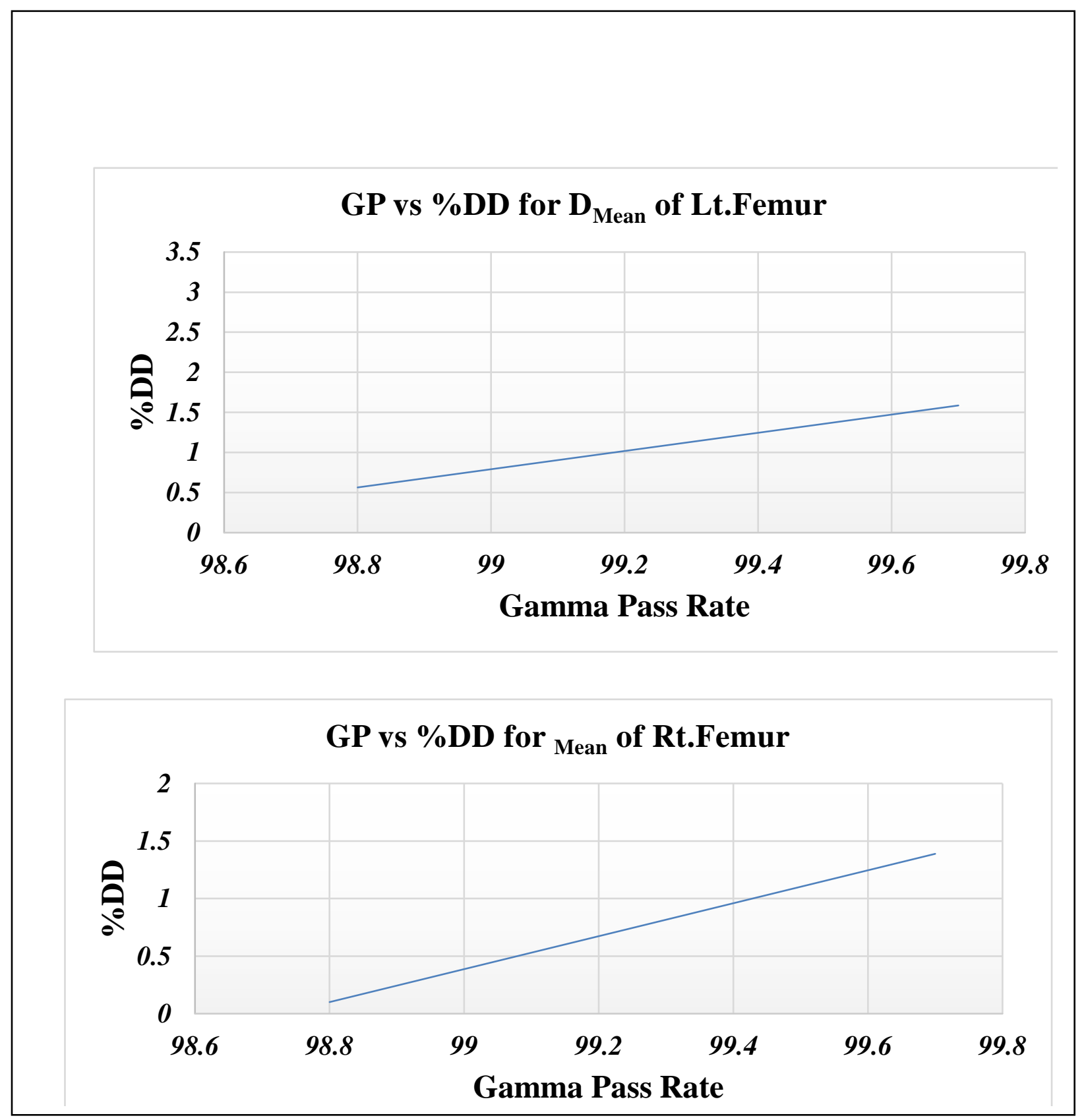

\section{Conclusion}

The purpose of this study was to use 3DVH software to compare the predicted dose by TPS with the predicted dose obtained by ArcCHECK dosimetric device using two treatment techniques: IMRT and VMAT. The use of the ArcCHECK phantom and the 3DVH software for delivery quality assurance can provide physicists with a wealth of information in a simple and 
straightforward manner, including the earlier simple 2D gamma index, the 3D gamma index, the gamma index for each ROI, the perturbed dose distribution, and several DVH-based matrices. The $\%$ DD was less than $3 \%$ for PTV and $4 \%$ for risk organs for VMAT technique while the IMRT technique recorded \%DD less than $2 \%$ for PTV and $4 \%$ for normal organs. 3DVH presented a somewhat better agreement with planned data for VMAT verifications with a mean GPR of $99.34 \%$ for $3 \% / 3 \mathrm{~mm}$ criterion compared to that of ArcCHECK.

The 3DVH had a mean gamma pass rate of $98.03 \%$ for IMRT verifications, which was $1.26 \%$ higher than those obtained by the ArcCHECK with a $3 \% / 3 \mathrm{~mm}$ acceptance criterion. The QA gamma analysis 3\%/3mm showed that in both VMAT and IMRT treatment plans, there was only a moderate-to-strong correlation (Pearson $r=0.49$ to 0.99 ) between the GP\% and the absolute \%DD. The precision of dose administration through the DVH for PTV and OARs volumes was successfully estimated using 3DVH. The t-test results between the calculated and predicted DVH values presented incomparable mean values $(\mathrm{p}<0.05)$ for the VMAT techniques, this suggests that there were systematic errors, however $D_{\text {Mean }}$ for PTV and bladder were comparable $(p>0.05)$ for the IMRT techniques. As VMAT is gradually being implemented, clinicians will be tasked with determining how to ensure patient safety through their quality assurance program Based on our results, VMAT is especially beneficial for prostate most cancers treatment.

\section{Acknowledgements}

The authors would like to thank the management of Dar Al Fouad Hospital for granting the opportunity to utilize their facility for this research work.

\section{Conflicts of Interest}

No conflicts of interest from all participating authors.

\section{List of Abbreviations:}

\begin{tabular}{|l|l|}
\hline TPS & Treatment Planning System \\
\hline IMRT & Intensity Modulated Radiation Therapy \\
\hline VMAT & Volumetric Modulated Arc Therapy \\
\hline PDP & Planned Dose Perturbation \\
\hline
\end{tabular}




\begin{tabular}{|c|c|}
\hline DVH & Dose Volume Histogram \\
\hline QA & Quality Assurance \\
\hline PTV & Planning Target Volume \\
\hline$\% \mathrm{DD}$ & Percentage Dose Differences \\
\hline $3 \mathrm{DVH}$ & Dose Volume Histogram Analysis Software \\
\hline GPR & Gamma Pass Rate \\
\hline $\mathrm{CT}$ & Computed Tomography \\
\hline ACPDP & ArcCHECK Planned Dose Perturbation \\
\hline RT & Radiation Therapy \\
\hline MLC & Multi-Leaf Collimator \\
\hline LINAC & Commercial Name Of the Medical linear Accelerator \\
\hline PDD & Percentage Depth Dose \\
\hline MU & Monitor Unit \\
\hline EPID & Electronic Portal Imaging Device \\
\hline 3D-CRT & Three-Dimensional Conformal Radiation Therapy \\
\hline DTA & Distance To Agreement \\
\hline DICOM & Digital Imaging and Communications in Medicine \\
\hline MV & Mega Volt \\
\hline ROI & Region Of Interest \\
\hline OAR & Organs At Risk \\
\hline $\mathrm{CW}$ & Clockwise \\
\hline CCW & Counterclockwise \\
\hline AAA & Anisotropic Analytical Algorithm \\
\hline TG & Task Group \\
\hline SNC & Sun Nuclear Corporation (SNC) Patient Software \\
\hline $\mathrm{DD}$ & Dose Difference \\
\hline SD & Standard Deviation \\
\hline
\end{tabular}




\section{References}

[1] Sweify, K., Fawzy, A., El-Fayoumy, H., Nofal, N. Evaluation of cell free circulating plasma DNA in prostate cancer. Journal of Scientific Research in Science, 34(part1): (2017) 108122. doi: $10.21608 /$ jsrs.2018.12760

[2] Chou, W., Puri D., \& Lee N., Intensity-modulated radiation therapy for head and neck cancer, Expert Rev. Anticancer Ther: (2005) 515-521.

[3] Khan, F.M., \& Gibbons, J. P.. Khan's the physics of radiation therapy (5th ed.). Lippincott Williams \& Wilkins (2014).

[4] Bhide, S., \& Nutting, C. Advances in radiotherapy for head and neck cancer. Oral Oncol,46, (2010) 439-441.

[5] Abdelaty, A., EL-Shershaby, A., Ashry, H., EL-Shahat, K. Evaluation of different physical parameters based on standard photon beam versus flattening filterfreein treatment cancer patients. Journal of Scientific Research in Science, 33(part1): (2016)171-183. doi: 10.21608/jsrs.2016.15537

[6] Miften, M., Olch A., Mihailidis D., et al. Tolerance limits and methodologies for IMRT measurement-based verification QA: recommendations of AAPM Task Group No. 218. Med Phys. 45 (2018) 53-83.

[7] Ali, Y., El Shahat, K., Abou Zeid, H., Ashry, H. A comparison of the gamma index and dose volume histogram of patient for IMRT/VMAT with different QA systems. Journal of Scientific Research in Science,34(1) (2017) 313-332. doi: 10.21608/jsrs.2018.14054.

[8] Ali, A. S., Dirkx, M. L., Cools, R. M., \& Heijmen, B. J.. Accurate IMRT fluence verification for prostate cancer patients using "in-vivo" measured EPID images and in room acquired kilovoltage cone-beam CT scans. Radiation Oncology (2013) 8(8) 211-218.

[9] Park, J. H., Kim, T. G., Min, S. K., and Park, B. Do, "Comparison of 3DVH Software with Two-dimensional Array Systems on Pretreatment Verification for Volumetric-modulated Arc Therapy," J. Nucl. Med. Radiat. Ther., (2016) 7(2).

[10] Chang, K. H., Kim, D. W., Choi, J. H., Shin, H.-B., Hong, C.-S., Jung, D. M., .. Lee, J. A.. Dosimetric Comparison of Four Commercial Patient-Specific Quality Assurance Devices for Helical Tomotherapy. Journal of the Korean Physical Society, 76(3) (2020) 257-263. doi:10.3938/jkps.76.257.

[11] Ezzell, G. A., Burmeister, J. W., Dogan, N., Losasso, T. J, Mechalakos, J. G., Mihailidis, D., Molineu, A., Palta, J. R., Ramsey, C. R., Salter, B. J., Shi, J., Xia, P., Yue, N. J., Xiao, Y. IMRT commissioning: Multiple institution planning and dosimetry comparisons, a report from AAPM Task Group 119. Med Phys;36, (2009) 5359-5373.

[12] Ghafarian, Melissa \& Price, Michael \& Morales-Paliza, Manuel. Comparison of pretreatment VMAT quality assurance with the integral quality monitor (IQM) and electronic portal imaging device (EPID). Journal of Applied Clinical Medical Physics. 22. 10.1002/acm2.13201. planningand dosimetry comparisons, a report from AAPM Task 
Group 119. Med. Phys, 36(11), (2021) 53-59.

[13] Fenoglietto, P., Laliberté, B., Aillères, N., Riou, O., Dubois, J. B., and Azria D., "Eight years of IMRT quality assurance with ionization chambers and film dosimetry: Experience of the montpellier comprehensive cancer center," Radiat. Oncol., (2011).

[14] Ĺtourneau, D., Publicover, J., Kozelka, J., Moseley, D.J., and Jaffray, D.A., "Novel dosimetric phantom for quality assurance of volumetric modulated arc therapy," Med. Phys., (2009).

[15] Low, D. A., Harms, W. B., Mutic, S., Purdy, J. A. A technique for the quantitative evaluation of dose distributions. Med Phys; 25, (1998) 656-661.

[16] Nelms, B.E \& Simon, J.A. A survey on IMRT QA analysis. Journal of Applied Clinical Medical Physics - J APPL CLIN MED PHYS. (2007) 8. 10.1120/jacmp.v8i3.2448.

[17] Both, S., Alecu, I., Stan, A., Alecu, M., \& Ciuraet, A. A study to establish reasonable action limits for patient-specific quality assurance in intensity-modulated radiation therapy. J Appl Clin Med Phys 8, (2007) 1-8.

[18] Sun Nuclear Corporation, "ArcCHECK ${ }^{\mathrm{TM}}$ User' s Guide. The Ultimate 4D QA Solution," (2009).

[19] Kruse, J. On the insensitivity of single field planar dosimetry to IMRT inaccuracies. Med Phys, 37(6) (2010) 2516-2525. doi:10.1118/1.3425781.

[20] Olch, A. J. "Evaluation of the accuracy of 3DVH software estimates of dose to virtual ion chamber and film in composite IMRT QA,” Med. Phys., (2012).

[21] Feygelman, V., Zhang, G., Stevens, C., \& Nelms, B. E. Evaluation of a new VMAT QA device, or the " $\mathrm{X}$ " and "O" array geometries. Journal of applied clinical medical physics, 12(2) (2011) 3346. https://doi.org/10.1120/jacmp.v12i2.3346.

[22] Guangjun, L., Zhang, Y., X. Jiang, S. B., Peng, G., \& Jiang, K. W. Evaluation of the ArcCHECK QA system for IMRT. Physica Medica, 29, (2013) 295-303.

[23] Infusino, E., Mameli, A., Conti, R., Gaudino, D., Stimato, G., Bellesi, L., .Trodella, L.. Initial experience of ArcCHECK and 3DVH software for RapidArc. Medical Dosimetry, 39, (2014) 276-281.

[24] F. Foroudi et al., "A dosimetric comparison of 3D conformal vs intensity modulated vs volumetric arc radiation therapy for muscle invasive bladder cancer,": (2012) 1-10. 
دراسة تقييمية للرسم البياني الحجمي للجرعة التي يتم حسابها و قياسها للعلاج الإثعاعي بإستخدام التقتيات الحديثة لمرضى سرطان البروستاتا

$$
\text { إبر اهيم أحمد الحمامصي: فيزيائي طبي "علاج إثعاعي" }
$$
أ.د. خالد محمد الشحات: أستاذ الفيزياء الطبية الإشعاعية ـ كلية الطب - جامعة الاز هر. أ.د. طارق محمد الاسوقي: أستاذ الفيزياء الإشعاعية ـ كلية البنات للآداب و العلوم و التربية ـ جامعةعين شمس. المرحومة أ.د. آمال محمود الثرشابي: أستاذ الفيزياء الإشعاعية ـ كلية البنات للآداب و العلوم و التربية ـ جامعةعين شمس. ملخص البحث تهذف هذه الدراسه الي استخدام برنامج عVH (Sun Nuclear Corporation, Melbourne, FL, USA) لمقارنة الجرعة المحسوبة بو اسطة نظام التخطيط العلاجي Eclipse مع الجرعة المقاسة التي تم الحصول عليها بواسطة جهاز قياس الجر عات ArcCHECK بإستخدام إثنين من تقنيات العلاج المتقدمه و هما : العلاج القوسي معدل الحجم RapidArc العلاج الإشعاعي منغير الثدة IMRT. تمت دراسة عشرين مريضا من مرضي سرطان البروستاتا الذين تمت معالجتهم باستخدام Eclipse العلاج القوسي و أعيدت حساباتهم باستخدام العلاج الأشعاعي متغير الثدة بواسطة نظام التخطيط العلاجي مئرئ

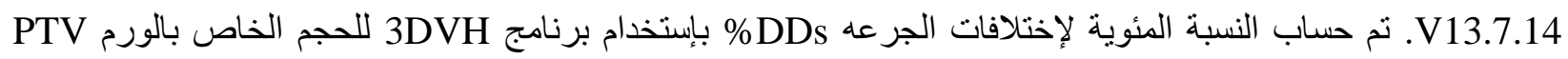

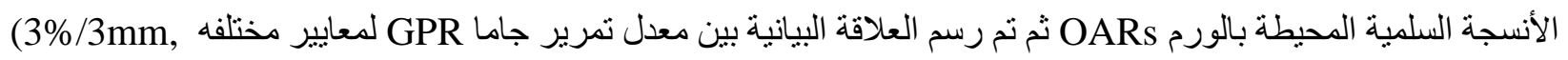
2\%/2mm and 1\%/1m ) بو اسطة برنامج 3DVH و الأخر المتوقع بواسطة نظام التخطيط العلاجي Eclipse لكل من حجم الورم و الأنسجة السليمة وجد أنة بإستخدام تقنية العلاج القوسي معدل الحجم أن النسبة المئوية لفرق الجرعة DD\% اقل من 3\% لحجم الورم PTV و $4 \%$ للانسجة السليمة OARs بينما في حالة إستخدام تقنية العلاج الاشعاعي متغير الثدة وجد أن النسبة المئوية DD لحجم الورم PTV و 4\% للانسجة السليمة. أظهر أستخدام برنامج 3DVH نتائج افضل الي حد كبير للبيانات المخطط لها للتحقق من من دقة العلاج القوسي معدل الحجم RapidArc بمعدل تحقيق 39.34\% للمعايير المنفق عليها 3\%,3mm مقارنة بالتي تم الحصول عليها بإستخدام جهاز قياس الجرعات ArcCHECK. لذلك توصي هذة الدر اسة باستخدام تقنيه العلاج القوسي معدل الحجم RapidArc لعلاج مرضى أور ام البروستاتا. 